Research Article

\title{
Wear Performance of Bionic Dimpled-Shape Pistons of Mud Pump
}

\author{
Xuejing Cheng, ${ }^{1,2}$ Tianyu Gao, ${ }^{1}$ Shaofeng $R u^{3}{ }^{3}$ and Qian Cong ${ }^{1}$ \\ ${ }^{1}$ Key Laboratory of Bionic Engineering, Ministry of Education, Jilin University, Changchun 130022, China \\ ${ }^{2}$ College of Mechanical and Electrical Engineering, Jilin Institute of Chemical Technology, Jilin 132022, China \\ ${ }^{3}$ Mechanical and Electrical Engineering College, Hainan University, Haikou 570228, China \\ Correspondence should be addressed to Shaofeng Ru; ru.shaofeng@163.com and Qian Cong; congqian@jlu.edu.cn
}

Received 13 June 2017; Accepted 28 September 2017; Published 27 December 2017

Academic Editor: Aniello Riccio

Copyright (c) 2017 Xuejing Cheng et al. This is an open access article distributed under the Creative Commons Attribution License, which permits unrestricted use, distribution, and reproduction in any medium, provided the original work is properly cited.

The piston is one of the parts that most easily become worn out and experience failure in mud pumps for well drilling. By imitating the body surface morphology of the dung beetle, this paper proposed a new type (BW-160) of mud pump piston that had a dimpled shape in the regular layout on the piston leather cup surface and carried out a performance test on the self-built test rig. Firstly, the influence of different dimple diameters on the service life of the piston was analyzed. Secondly, the analysis of the influence of the dimple central included angle on the service life of the piston under the same dimple area density was obtained. Thirdly, the wear of the new type of piston under the same wear time was analyzed. The experimental results indicated that the service life of the piston with dimples on the surface was longer than that of L-Standard pistons, and the maximum increase in the value of service life was $92.06 \%$. Finally, the Workbench module of the software ANSYS was used to discuss the wear-resisting mechanism of the new type of piston.

\section{Introduction}

The mud pump is the "heart" of the drilling system [1]. It has been found that about $80 \%$ of mud pump failures are caused by piston wear. Wear is the primary cause of mud pump piston failure, and improving the wear-resisting performance of the piston-cylinder friction pair has become the key factor to improve the service life of piston.

Most of the researchers mainly improve the service life of piston through structural design, shape selection, and material usage $[1,2]$. However, the structure of mud pump piston has been essentially fixed. The service life of piston is improved by increasing piston parts and changing the structures of the pistons. However, the methods have many disadvantages, for example, complicating the entire structure, making piston installation and change difficult, increasing production and processing costs, and so on. All piston leather cup lips use rubber materials, and the material of the root part of the piston leather cup is nylon or fabric; many factors restrict piston service life by changing piston materials [3]. Improving the component wear resistance through surface texturing has been extensively applied in engineering. Under multiple lubricating conditions, Etsion has studied the wear performance of the laser surface texturing of end face seal and reciprocating automotive components [4-6]. Ren et al. have researched the surface functional structure from the biomimetic perspective for many years and pointed out that a nonsmooth surface structure could improve the wear resistance property of a friction pair [ $[7,8]$. Our group has investigated the service life and wear resistance of the striped mud pump piston, and the optimal structure parameters of the bionic strip piston have improved piston service life by $81.5 \%$ [9]. Wu et al. have exploited an internal combustion engine piston skirt with a dimpled surface, and the bionic piston has showed a $90 \%$ decrease in the average wear mass loss in contrast with the standard piston [10]. Gao et al. have developed bionic drills using bionic nonsmooth theory. Compared with the ordinary drills, the bionic drills have showed a $44 \%$ increase in drilling rate and a $74 \%$ improvement in service life [11]. The 


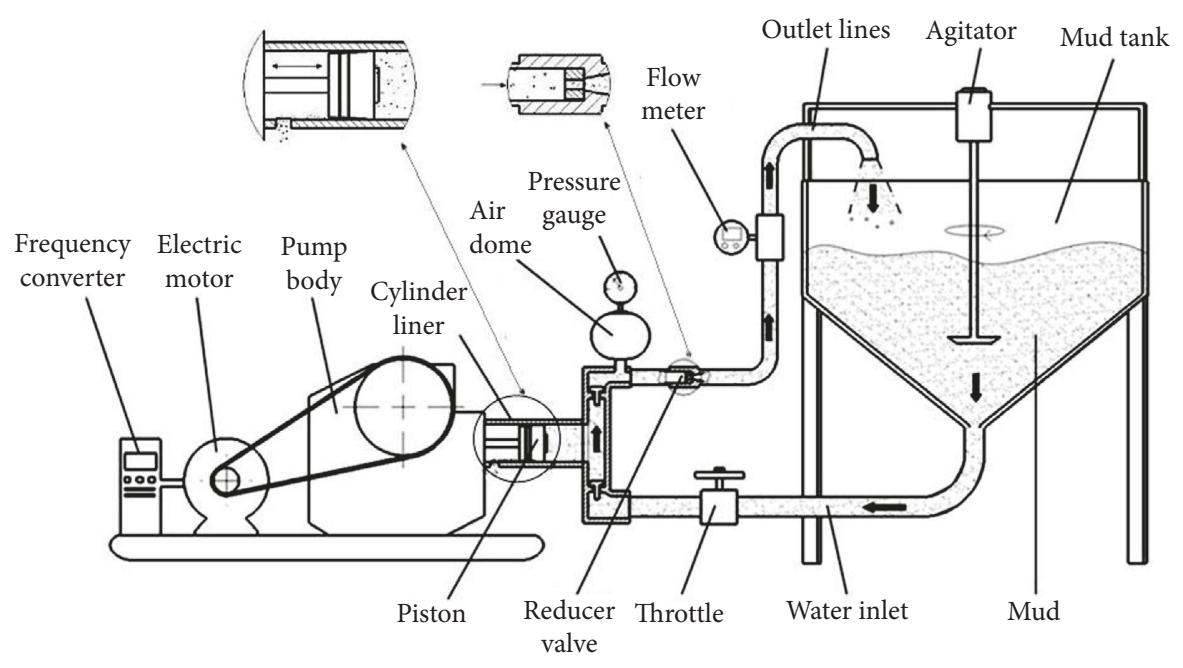

Figure 1: Principle of test rig.

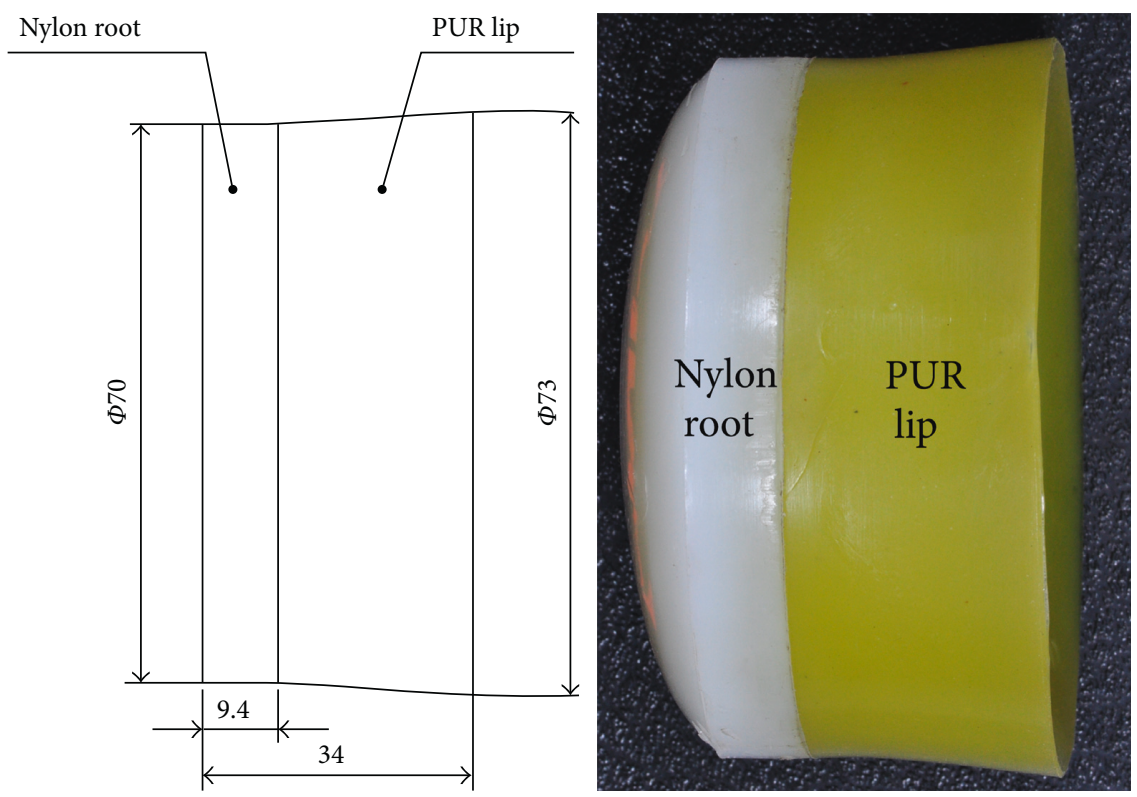

FIgURE 2: Test piston size and its original picture.

present researches indicate that microstructures, like superficial dimples and stripes, contribute to constituting dynamic pressure to improve the surface load-carrying capacity and the wear resistance of the friction pair [12-21].

In nature, insects have developed the excellent wearresistant property in the span of billions of years. For instance, the partial body surface of the dung beetle shows an irregularly dimpled textured surface with the excellent wear-resistant property that is conducive to its living environment $[7,8,22]$. The dung beetle, which is constantly active in the soil, shows a body surface dimple structure that offers superior drag reduction. These dimples effectively reduce the contact area between the body surface and the soil. Moreover, the friction force is reduced. Therefore, the dung beetle with the nonsmooth structure provides the inspiration to design the bionic mud pump piston. This paper proposed a new type of piston with dimpled morphology on its surface and conducted a comparative and experimental study of different surface dimpled shapes, thus opening up a new potential to improve the service life of the mud pump piston.

\section{Experiment}

2.1. Design of Test Rig and Test Method. A closed-loop circulatory system was used in the test rig, which was built according to the national standard with specific test requirements. The test rig consisted of triplex single-acting mud pump, mud tank, in-and-out pipeline, reducer valve, flow meter, pressure gauge, and its principle, as shown in Figure 1. Both the pressure and working stroke of the BW-160 mud pump are smaller than those of the large-scale mud pump, but their operating principles, structures, and working processes are identical. Therefore, the test selected 


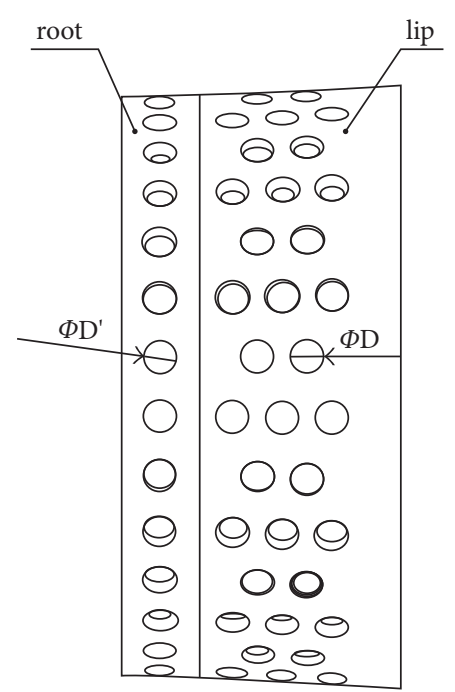

(a)

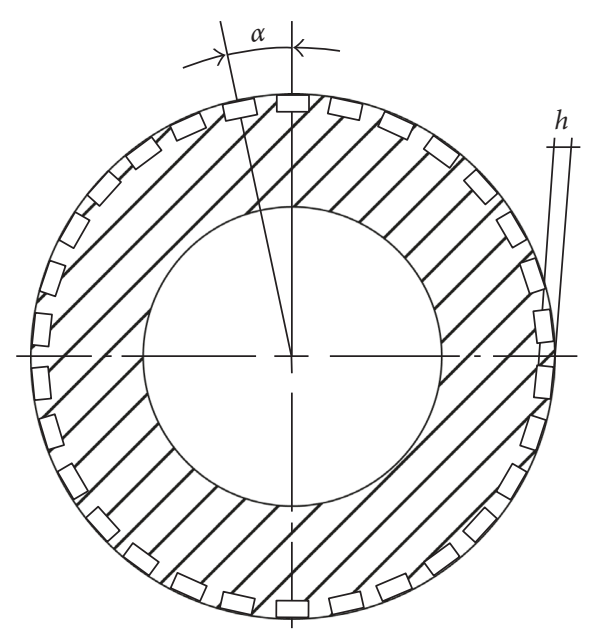

(c)

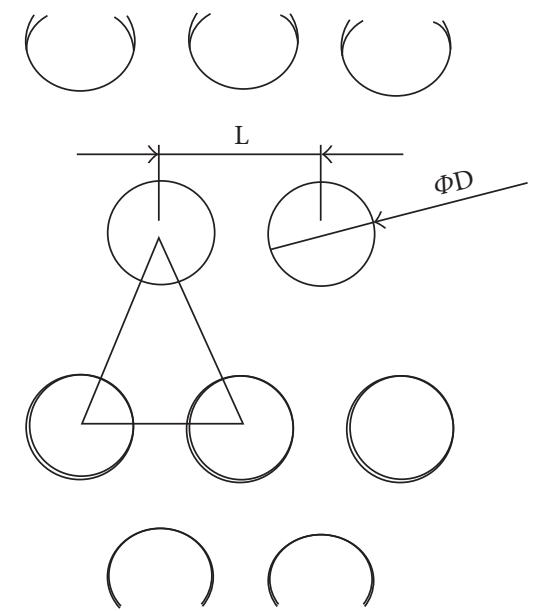

(b)

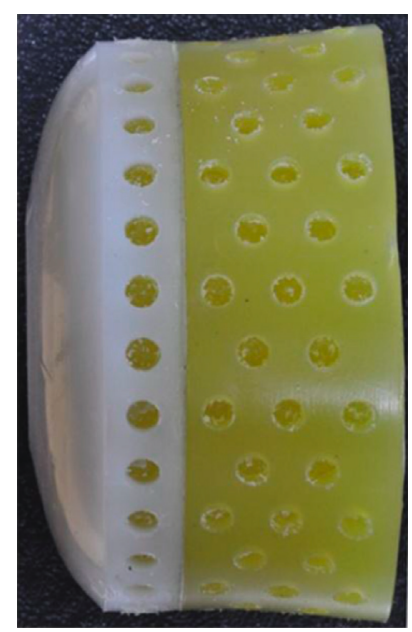

(d)

FIGURE 3: Schematic of dimpled piston: (a) dimpled layout of piston, (b) dimpled array form diagram, (c) cross section view of the piston leather cup, and (d) original picture of dimpled piston.

a relatively small BW-160 triplex single-acting mud pump piston as a research object, and the test results and conclusion were applicable to large-scale mud pump pistons. The cylinder diameter, working stroke, reciprocating motion velocity of piston, maximum flow quantity, and working pressure of the BW-160 triplex single-acting mud pump were $70 \mathrm{~mm}, 70 \mathrm{~mm}, 130 \mathrm{times} / \mathrm{min}, 160 \mathrm{~L} / \mathrm{min}$, and $0.8-$ $1.2 \mathrm{MPa}$, respectively.

The mud pump used in the test consisted of water, bentonite (meeting the API standard), and quartz sand with a diameter of $0.3-0.5 \mathrm{~mm}$ according to actual working conditions. The specific gravity of the prepared mud was 1.306 , and its sediment concentration was $2.13 \%$. Whether mud leakage existed at the venthole in the tail of the cylinder liner of the mud pump was taken as the standard of piston failure. Observation was made every other half an hour during the test process. It was judged that the piston in the cylinder failed when mud leaked continuously; its service life was recorded, and then it was replaced with the new test piston and cylinder liner. The BW-160 mud pump is a triplex single-acting mud pump. The wear test of three pistons could be simultaneously conducted.

2.2. Test Model Design and Test Program. The mud pump piston used in the test consisted of a steel core, leather cup, pressing plate, and clamp spring. The leather cup consisted of the lip part of polyurethane rubber and the root part of nylon; the outer diameter on the front end of the piston was $73 \mathrm{~mm}$, and the outer diameter of the piston tail was $70 \mathrm{~mm}$, as shown in Figure 2. We proceeded in two parts during the design of the dimpled layout pattern because the piston leather cup consisted of two parts whose materials were different. The dimples at the lip part of the leather cup adopted an isosceles triangle layout pattern, and the dimples at the root part were arranged at the central part of its axial 
TABle 1: Influence of different dimple diameters on piston service life.

\begin{tabular}{lcccccc}
\hline Piston number & $\begin{array}{c}\text { Diameter of dimple } \\
\text { at lip, } D(\mathrm{~mm})\end{array}$ & $\begin{array}{c}\text { Spacing, } \\
L(\mathrm{~mm})\end{array}$ & $\begin{array}{c}\text { Central included } \\
\text { angle, } \alpha\left(^{\circ}\right)\end{array}$ & $\begin{array}{c}\text { Diameter of dimple } \\
\text { at root, } D^{\prime}(\mathrm{mm})\end{array}$ & $\begin{array}{c}\text { Average service } \\
\text { life of piston }(h)\end{array}$ & $\begin{array}{c}\text { Increased service } \\
\text { life }(\%)\end{array}$ \\
\hline L-Standard & 0 & 0 & 0 & 0 & 54.67 & - \\
L-D1 & 1.5 & 5.5 & 12 & 0 & 57.17 & 76.83 \\
L-D2 & 3 & 5.5 & 12 & 0 & 87.83 & 40.53 \\
L-D3 & 4.5 & 5.5 & 12 & 0 & 80.17 & 48.47 \\
L-D4 & 3 & 5.5 & 12 & 3 & 05 \\
\hline
\end{tabular}

TABLE 2: Influence of central included angle on piston service life.

\begin{tabular}{lcccccc}
\hline Piston number & $\begin{array}{c}\text { Diameter of dimple } \\
\text { at lip, } D(\mathrm{~mm})\end{array}$ & $\begin{array}{c}\text { Spacing, } \\
L(\mathrm{~mm})\end{array}$ & $\begin{array}{c}\text { Central included } \\
\text { angle, } \alpha\left(^{\circ}\right)\end{array}$ & $\begin{array}{c}\text { Diameter of dimple } \\
\text { at root, } D^{\prime}(\mathrm{mm})\end{array}$ & $\begin{array}{c}\text { Average service } \\
\text { life of piston }(h)\end{array}$ & $\begin{array}{c}\text { Increased service } \\
\text { life }(\%)\end{array}$ \\
\hline L-Standard & 0 & 0 & 0 & 0 & 54.67 & 76.83 \\
L-D2 & 3 & 5.5 & 12 & 0 & 105.00 & 40.53 \\
L-S1 & 1.5 & 5.5 & 3 & 0 & 59.50 \\
L-S2 & 4.5 & 5.5 & 27 & 0 & 92.06 \\
\hline
\end{tabular}

TABLE 3: Wear patterns of pistons with different dimple diameters.

\begin{tabular}{lccccc}
\hline Piston number & $\begin{array}{c}\text { Diameter of dimple } \\
\text { at lip, } D(\mathrm{~mm})\end{array}$ & $\begin{array}{c}\text { Spacing, } \\
L(\mathrm{~mm})\end{array}$ & $\begin{array}{c}\text { Central included } \\
\text { angle, } \alpha\left(^{\circ}\right)\end{array}$ & $\begin{array}{c}\text { Diameter of dimple } \\
\text { at root, } D^{\prime}(\mathrm{mm})\end{array}$ & $\begin{array}{c}\text { Average wear mass } \\
\text { percentage of piston }\end{array}$ \\
\hline L-Standard & 0 & 0 & 0 & 0 & 6.98 \\
T1 & 1.5 & 5.5 & 12 & 1.5 & 6.59 \\
T2 & 3 & 5.5 & 12 & 3 & 4.22 \\
T3 & 4.5 & 5.5 & 12 & 4.5 & 3.83 \\
\hline
\end{tabular}

length, as shown in Figure 3(a). Dimple diameter $\left(D, D^{\prime}\right)$, distance $(L)$, depth $(h)$, and central included angle $(\alpha)$ are shown in Figure 3. The dimples on the piston surface were processed by the CNC machining center. Since then, the residual debris inside the dimples was cleaned.

The test program was divided into three contrast groups. The dimple depth in the test was $2.5 \mathrm{~mm}$. Table 1 shows the comparison between the service life of dimpled piston with different diameters L-D1, L-D2, and L-D3 and that of the L-Standard piston. In Table 1, a comparison between the L-D4 piston with dimples at the leather cup root and the L-D2 piston is shown to study the influence of dimples at the leather cup root on the piston service life. Table 2 gives the influence of the dimple central included angle on piston service life when the dimple area density was the same by taking the L-D2 area density as a criterion. Table 3 displays a comparison of the wear patterns of pistons with different dimple diameters and L-Standard pistons under the same wear time. This object of the group test is to analyze the dimple wear pattern at the leather cup root under the existence of dimples at the roots of all leather cups.

\section{Results and Discussion}

3.1. Influence of Dimple Diameter on Piston Service Life. Table 1 shows that average service lives of L-Standard, L-D1, L-D2, and L-D3 were $54.67 \mathrm{~h}, 57.17 \mathrm{~h}, 76.83 \mathrm{~h}$, and $87.83 \mathrm{~h}$, respectively. Therefore, the mud pump pistons with dimples provide longer service life than the L-Standard piston. As the dimple diameter increases, the piston service life was improved, and the largest percentage increase of the service life was $60.65 \%$. The service life of the L-D4 piston was about $81.17 \mathrm{~h}$, which increased by $7.94 \%$ compared with that of the L-D2 piston, indicating that the piston with dimples at the leather cup root could improve piston service life.

Figure 4 illustrates the surface wear patterns of pistons with different dimple diameters in the service life test. Figures $4(\mathrm{a})$ and $4\left(\mathrm{a}^{\prime}\right)$ show wear patterns on the surface of the L-Standard piston. This figure shows that intensive scratches existed in parallel arrangement on the piston leather cup surface, enabling high-pressure mud to move along the scratches from one end of the piston to the other easily, which accelerated the abrasive wear failure with the abrasive particles of the piston. Figures $4(\mathrm{~b}), 4\left(\mathrm{~b}^{\prime}\right), 4(\mathrm{c}), 4\left(\mathrm{c}^{\prime}\right), 4(\mathrm{~d})$, and $4\left(d^{\prime}\right)$ show the wear patterns of the leather cup surfaces of L-D1, L-D2, and L-D3 pistons, respectively. Figures 4(b), $4\left(b^{\prime}\right), 4(c), 4\left(c^{\prime}\right), 4(d)$, and $4\left(d^{\prime}\right)$ show that the scratches on the leather cup surface became shallower and sparser and the surface wear patterns improved more obviously as the dimple diameter increased. If the piston leather cup surface strength was not affected to an extent as the dimple diameter increased, the reduced wear zone near the dimple would become greater and greater, indicating that the existence of dimples changed the lubricating status of the leather cup surface, their influence on nearby dimpled parts was more obvious, and they played active roles in improving the service life of the piston.

Figure 5 displays the wear patterns of the leather cup root parts of the L-D4 and L-D2 test pistons. The wear patterns of 


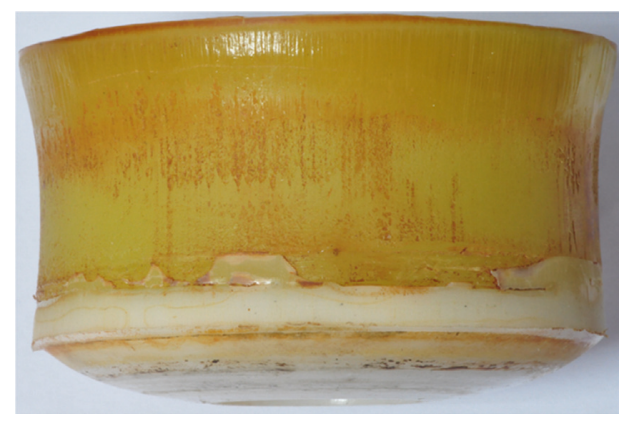

(a)

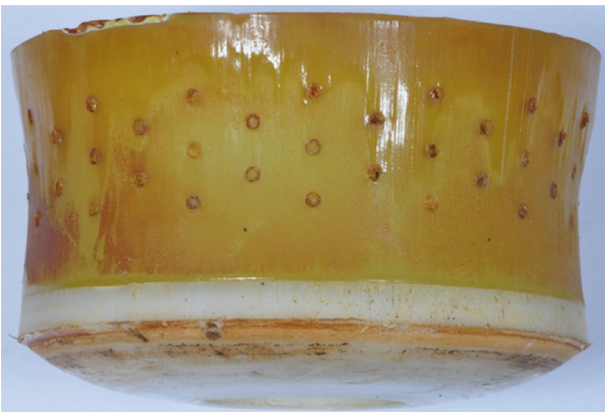

(b)

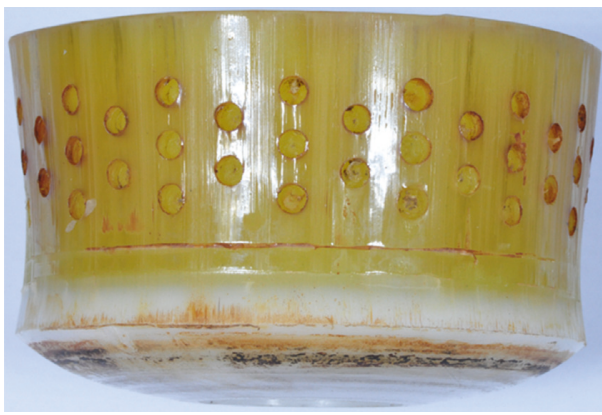

(c)

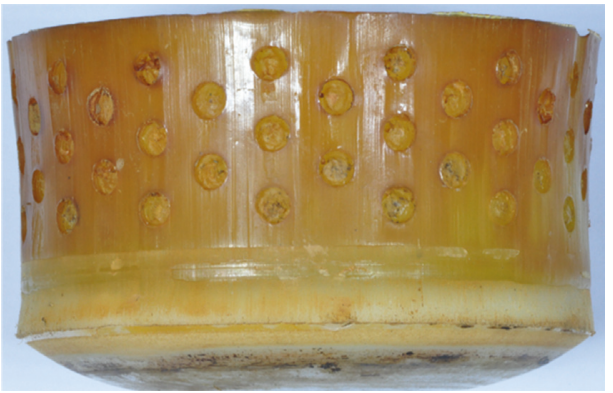

(d)

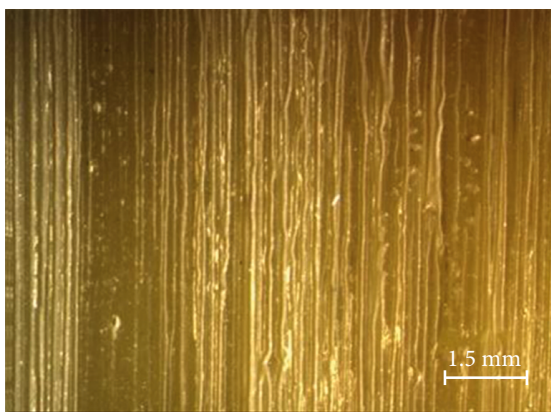

$\left(a^{\prime}\right)$

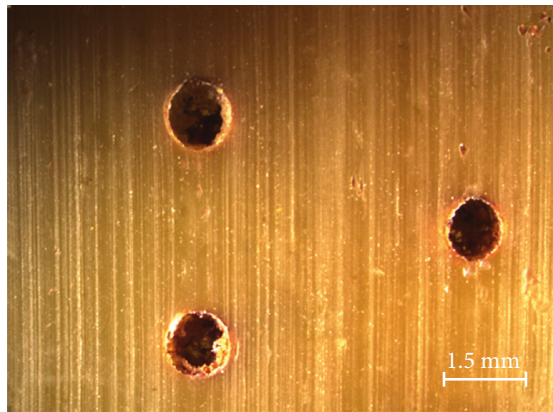

$\left(\mathrm{b}^{\prime}\right)$

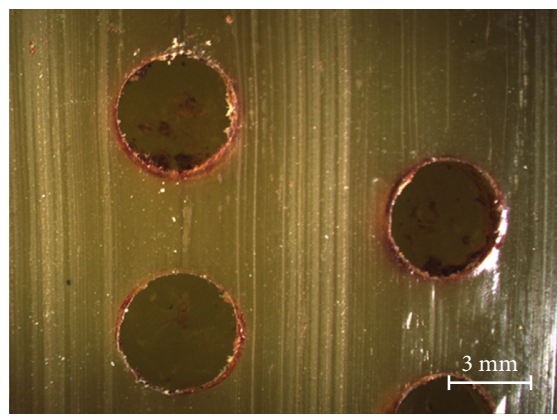

$\left(c^{\prime}\right)$

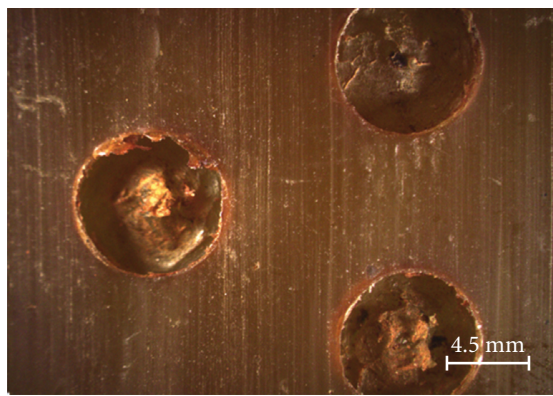

$\left(d^{\prime}\right)$

FiguRE 4: Surface wear patterns of pistons with different dimple diameters in the service life test: (a) L-Standard piston, (b) L-D1 piston, (c) L-D2 piston, and (d) L-D3 piston. $\left(a^{\prime}, b^{\prime}, c^{\prime}, d^{\prime}\right)$ are partial enlarged pictures of (a, b, c, d).

the nylon root parts of the L-D4 pistons are fewer than those of the L-D2 pistons, as shown in Figure 5. When the leather cup squeezed out high-pressure mud as driven by the piston steel core, it experienced radial squeezing while experiencing axial wear. Therefore, the area with the most serious wear was the piston leather cup root part, and the friction force at the leather cup root was much greater than that at the other areas. The rapid wear at the root decreased the piston 


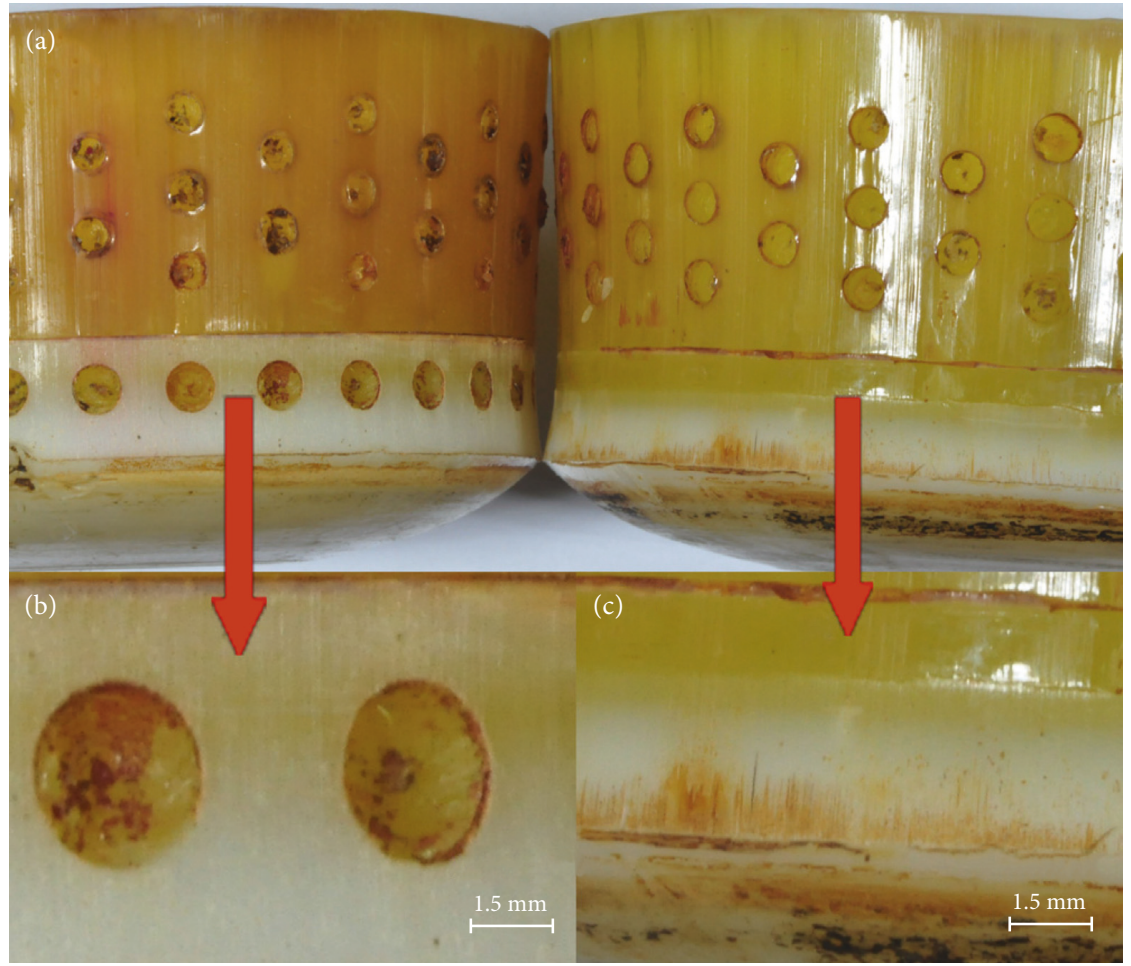

FIGURE 5: Wear patterns of the piston leather cup root with and without dimples: (a) comparison chart of root wear of the L-D4 and L-D2 pistons, (b) partial enlarged diagram of root wear of the L-D4 piston, and (c) partial enlarged diagram of root wear of the L-D2 piston.

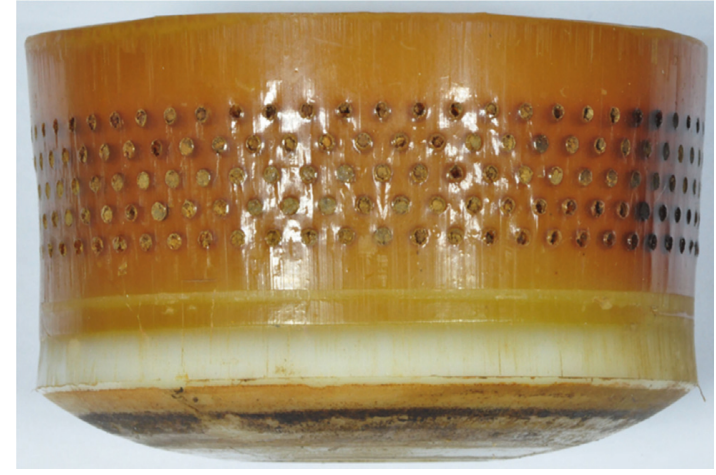

(a)

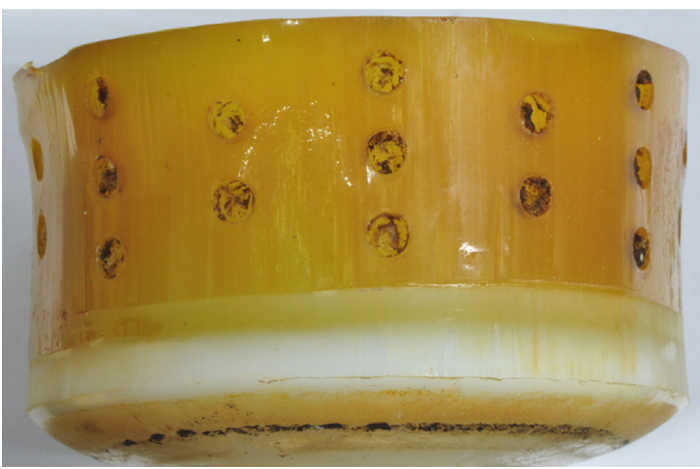

(b)

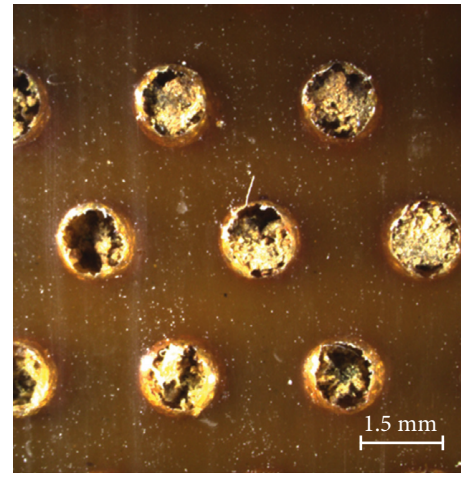

$\left(a^{\prime}\right)$

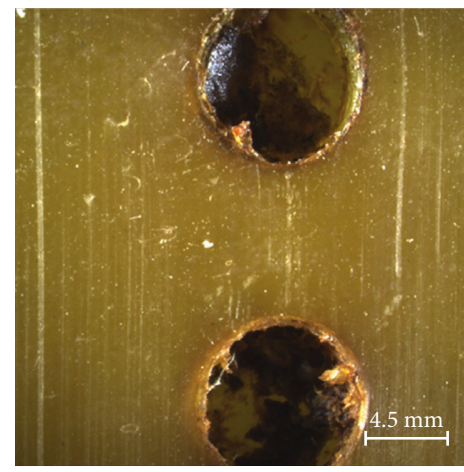

$\left(b^{\prime}\right)$

FIGURE 6: Wear patterns of pistons with different dimple central included angles under the same area density: (a) L-S1 piston and (b) L-S2 piston. $\left(a^{\prime}, b^{\prime}\right)$ were partial enlarged pictures of $(a, b)$. 


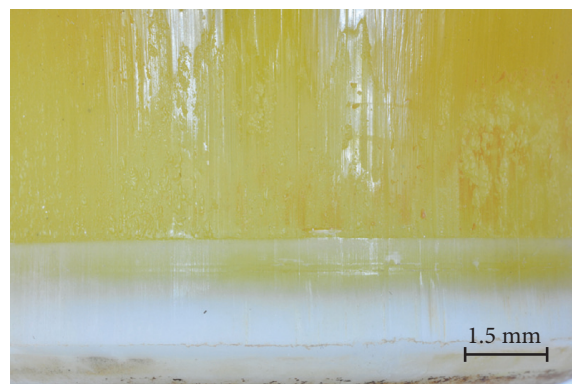

(a)

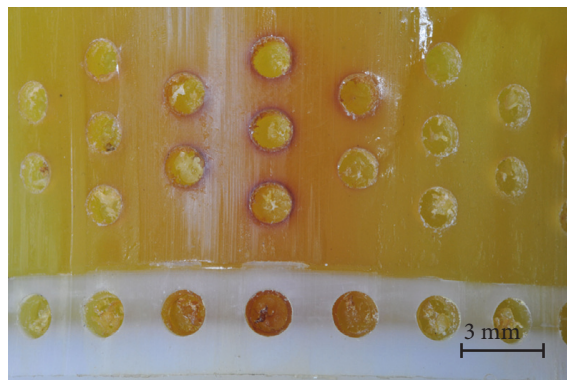

(c)

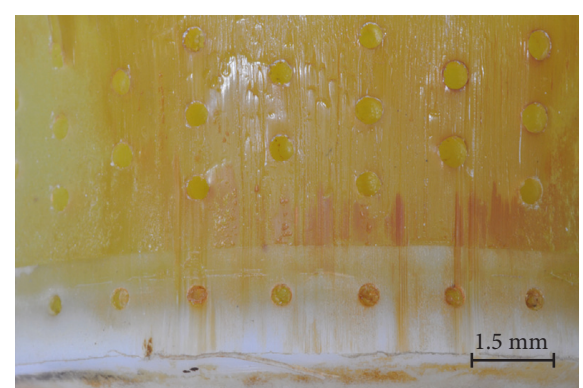

(b)

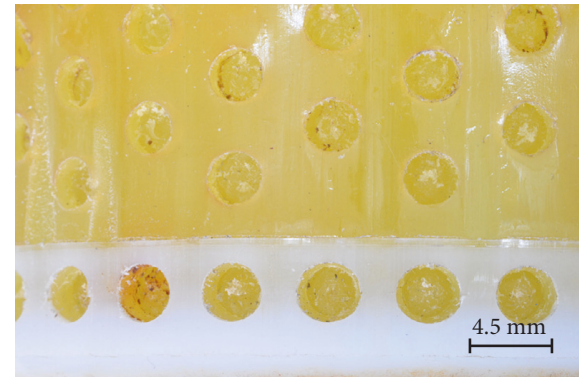

(d)

FIGURE 7: Wear patterns of the piston leather cup under the same wear time: (a) L-Standard piston, (b) T1 piston, (c) T2 piston, and (d) T3 piston.

TABLE 4: Grid nodes and elements.

\begin{tabular}{lcc}
\hline Piston no. & Node & Element \\
\hline L-Standard piston & 172470 & 119858 \\
L-S1 piston & 221866 & 116970 \\
L-D1 piston & 391476 & 272002
\end{tabular}

load-carrying capacity and then affected the service life of piston. The dimples at the piston leather cup root could reduce the wear of the piston leather cup root and improve the service life of piston.

\subsection{Influence of the Dimple Central Included Angle on Piston} Service Life under the Same Area Density. Table 2 indicates that the average service life of the L-S1 piston was $105.00 \mathrm{~h}$, which is about twice that of the L-S2 piston $(59.50 \mathrm{~h})$ and was obviously improved in comparison with that of the L-D2 piston $(76.83 \mathrm{~h})$, indicating that, under the same dimple area density, the smaller the dimple central included angle was, that is, the closer the circumferential arrangement of dimples was, the longer the service life of the piston would be, and the increase of the maximum value of service life was $92.06 \%$.

Figure 6 shows the surface wear patterns of the L-S1 and L-S2 test pistons. In Figures $6(\mathrm{a})$ and $6\left(\mathrm{a}^{\prime}\right)$, the scratches on the piston leather cup surface became sparse and shallow in the dimpled area. Figures $6(\mathrm{~b})$ and $6\left(\mathrm{~b}^{\prime}\right)$ show that the wear was slight in the area close to the dimples. The farther the scratches were from the dimpled area, the denser and deeper the scratches would be. The L-S1 piston had a small dimple central included angle, which was arranged more closely on the piston surface. The lubricating effects of oil storage in each row of dimples were overlaid very well, which was equivalent to amplifying the effect of each row of dimples in Figure 6(b), making the wear on the whole piston leather cup surface slight, preventing the entry of high-pressure mud into the frictional interface, and lengthening the service life of piston.

\subsection{Comparison of Wear Patterns of Pistons with Different} Dimple Diameters under the Same Wear Time. Before all pistons have not failure, T1, T2, T3, and L-Standard experienced equal-time wear. This test set the wear time at $30 \mathrm{~h}$. The piston leather cup mass was $W_{0}$ before the test. After the test, the mass of the piston leather cup was $W_{1}$. During the test, the wear loss of the piston leather cup was $W=W_{0}-W_{1}$. The wear mass percentage of the test piston leather cup was calculated as $\varphi=W / W_{0}$. The test results are shown in Table 3 .

Table 3 shows that the average wear mass percentages of the L-Standard, T1, T2, and T3 pistons were 6.98\%, 6.59\%, $4.22 \%$, and $3.83 \%$, respectively. The wear mass percentages of the dimpled pistons were basically lower than those of the L-Standard piston and decreased as the dimple diameter increased. Figure 7 shows the wear patterns of the piston leather cup. The wear rules displayed in Figure 7 were similar to those displayed in Figure 4. The only difference was that the wear in Figure 7 was slighter than that in Figure 4. Based on the wear under the same time, the existence of dimples reduced the piston wear.

3.4. Analysis of Wear-Resisting Mechanism of Dimpled Piston of Mud Pump. During the operation of the mud pump piston, the outside surface of the piston leather cup comes in 


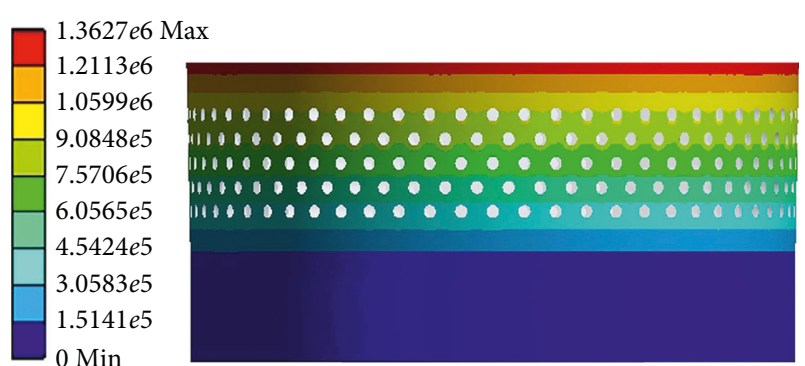

(a)

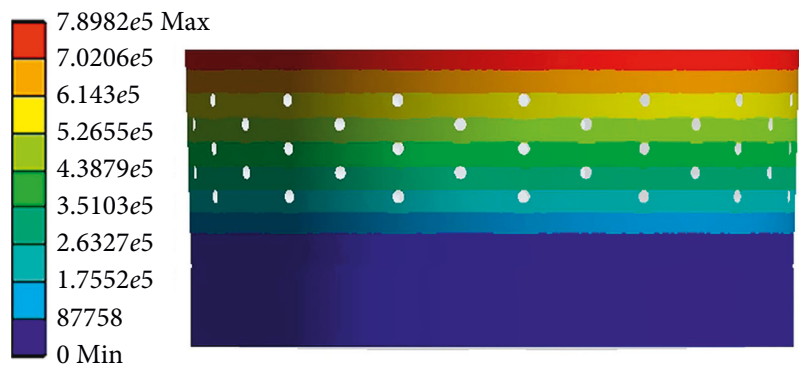

(b)
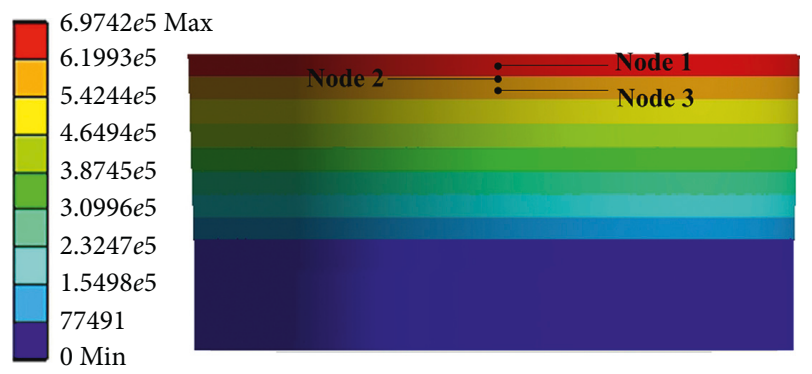

(c)

Figure 8: Contact pressure diagrams of the L-Standard piston and dimpled pistons: (a) L-S1 piston, (b) L-D1 piston, and (c) LStandard piston.

contact with the inner wall of the cylinder liner and simultaneously moves to push the mud. The lip part of the piston leather cup mainly participated in the piston wear and exerted a sealing effect, while the piston root part mainly exerted centralizing and transitional effects. In the mud discharge stroke, the lip part of the piston experienced a "centripetal effect," and a gap was generated between the lip part and the cylinder liner. The greater the contact pressure between the lip part and cylinder liner of the piston was, the smaller the gap was, and the entry of high-pressure mud into the contact surface between the piston and cylinder liner was more difficult. The piston root easily experienced squeezing under high pressure, and the smaller the equivalent stress caused by the piston root was, the more difficult the squeezing to occur. Hence, the contact pressure at the lip part of the piston and the equivalent stress at the root were analyzed, and they would provide a theoretical basis for the piston wear-resisting mechanism. The ANSYS Workbench module was used to perform a comparative analysis between the contact pressure at the lip part and the equivalent stress at the root of the three kinds of pistons (i.e., L-Standard piston, L-S1 piston, and L-D1 piston). The

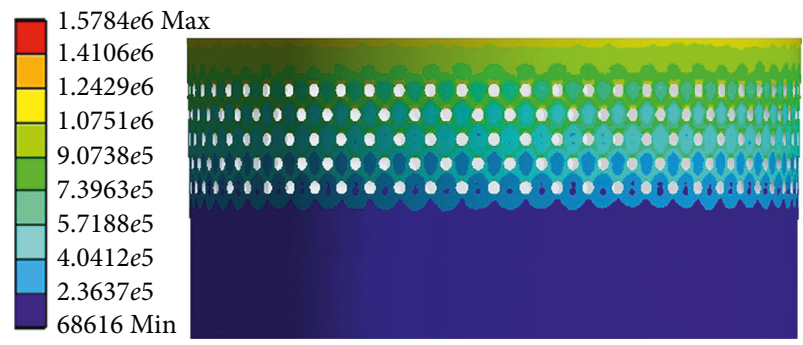

(a)

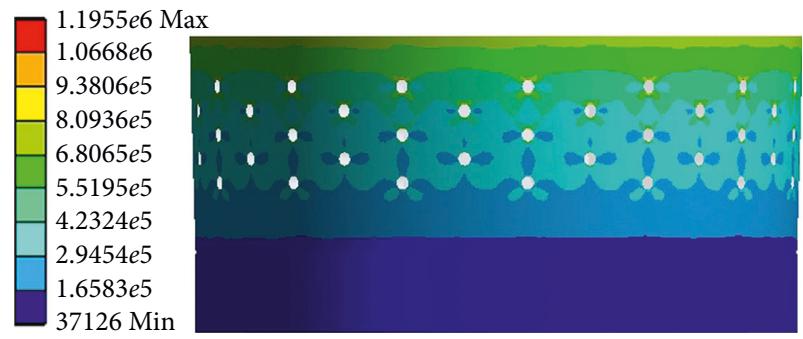

(b)
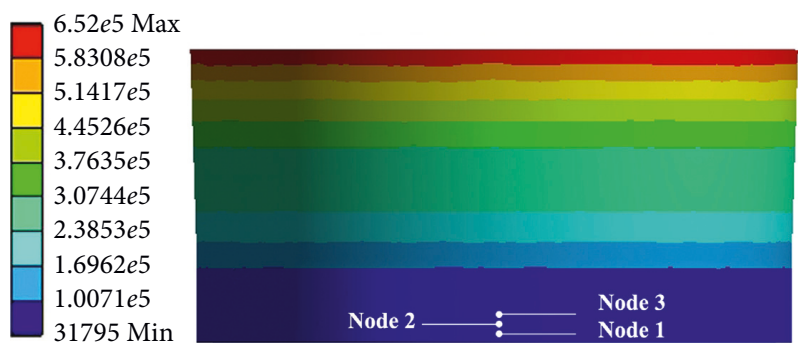

(c)

FIgURE 9: Equivalent stress diagrams of the L-Standard piston and dimpled pistons: (a) L-S1 piston, (b) L-D1 piston, and (c) LStandard piston.

service life of the L-S1 piston exhibited the best improvement effect, whereas that of the L-D1 piston demonstrated the worst improvement effect. The piston adopted a $1 \mathrm{~mm}$ hexahedral grid, and the grid nodes and elements are as shown in Table 4.

We could obtain the contact pressure nephograms of the three pistons by analyzing the contact pressure of the lip parts of the L-Standard piston and two dimpled pistons, as shown in Figure 8.

The contact pressure nephograms of the three pistons indicate that the dimpled structure on the piston surface changed the distribution state of contact pressure. Three nodes were selected at the same position of each piston to obtain the contact pressure values. The node positions are shown in Figure 8(c), and the average pressure value of three nodes was the pressure value at the lip part of this piston. The contact pressure value of the L-Standard piston was $0.6027 \mathrm{MPa}$ and that of the L-D1 and L-S1 pistons was $0.6840 \mathrm{MPa}$ and $1.0994 \mathrm{MPa}$, respectively. Compared with the L-Standard piston, the contact pressure at the lip part of the L-S1 piston increased, the gap between the piston and cylinder liner became small, which could effectively prevent abrasive particles from participating in the wear and resulting in piston failure, and there was 


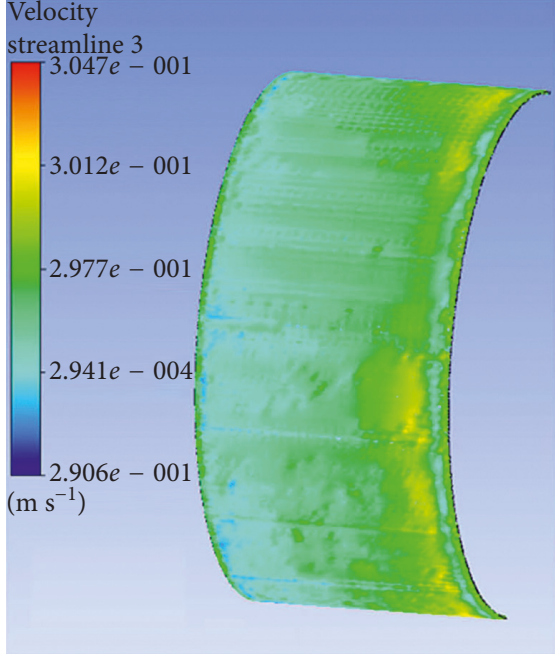

(a)

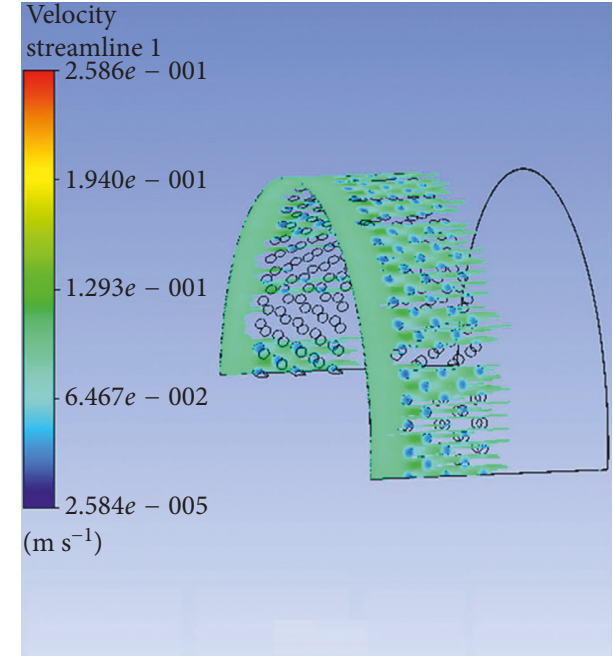

(b)

Figure 10: Piston surface streamline: (a) L-Standard piston and (b) dimpled piston.

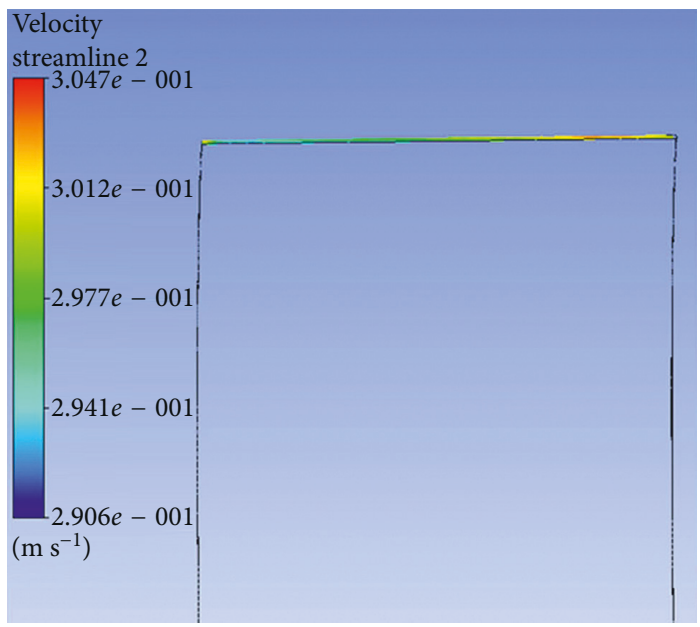

(a)

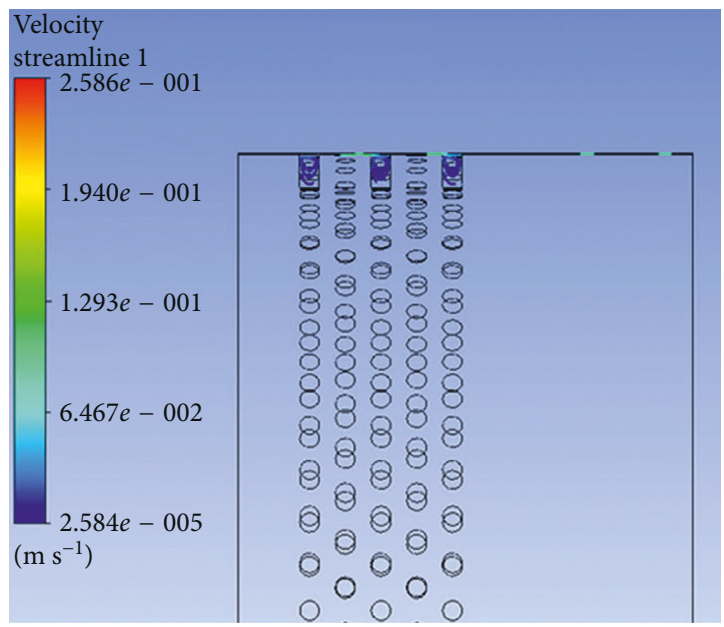

(b)

Figure 11: Piston cross section streamline: (a) L-Standard piston and (b) dimpled piston.

greater improvement in the service life of piston. The contact pressure of the L-D1 piston did not increase too much, and the degree of improvement of the piston service life was not obvious.

An equivalent stress analysis of the root parts of the L-Standard piston and two dimpled pistons was conducted to obtain the equivalent stress nephograms of the three pistons, as shown in Figure 9.

The equivalent stress nephograms of the three pistons show that the root of the L-Standard piston bore great stress and was easily squeezed, which accelerated piston wear and reduced piston service life. The dimpled structure could reduce the equivalent stress at the piston root and lengthen piston service life. Three nodes were selected in the same root positions of the three pistons. Their positions are as shown in Figure 9(c). The average value of the equivalent stresses of the three nodes was the equivalent stress value at the root of this piston. The equivalent stress value of the L-Standard piston was $0.1093 \mathrm{MPa}$, that of the L-D1 piston was $0.1066 \mathrm{MPa}$, and that of the L-S1 piston was $0.0922 \mathrm{MPa}$. The dimpled structure of the L-S1 piston could reduce the equivalent stress at the root and reduce the occurrence of root squeezing wear. The equivalent stress value of L-D1 did not decrease too much, and the degree of improvement of the piston service life was not obvious.

The lubricating oil on the mud pump piston surface could reduce the wear of piston and cylinder liner and improve the service life of pistons with the reciprocating movement. The lubricating oil would eventually run off and lose lubricating effect, which would result in piston wear. The finite element fluid dynamics software CFX was used to establish the fluid domain model of the dimpled and 
L-Standard pistons and analyze the lubricating state on the piston surface. The piston surface streamlines are shown in Figure 10. This figure shows that the lubricating fluid did not experience truncation or backflow phenomenon when passing the surface of the L-Standard piston. When the lubricating fluid flowed through the surface of the dimpled piston, it presented a noncontinuous process. Its flow velocity at the dimpled structure slowed down obviously because it was blocked by the dimpled structure.

Figure 11 shows the piston cross section streamline. This figure shows that the existence of dimples changed the distribution status of the lubricating flow fields on the contact surface between the piston and cylinder liner. The lubricating oil entered the dimpled structure in a large quantity, and the flow velocity slowed down. The dimpled structure on the piston surface enlarged the storage space of the lubricating oil and made it difficult for the lubricating oil inside the dimpled structure to be taken away by the cylinder liner to improve the lubricating conditions of the friction pair interface, reduce the frictional resistance between the piston and cylinder liner, reduce wear, and improve the piston service life.

When the piston moved in the cylinder liner, a small quantity of solid particles in mud entered gap of piston and cylinder liner and participated in abrasion. The dimpled structure on the piston surface could store some abrasive particles (as shown in Figure 6( $\left.\mathrm{a}^{\prime}\right)$ ) during the piston wear process to prevent these particles from scratching the piston and cylinder liner and generating gullies, thus avoiding secondary damage to the piston and cylinder liner and improving the piston service life.

\section{Conclusion}

This paper presented a dimpled-shape mud pump piston; that is, the piston leather cup surface had a dimpled array morphology in regular arrangement. The experimental results can provide the basic data for design engineering of the mud pump piston with a long service life. The comparative analyses of service life and wear patterns for dimpled mud pump pistons and L-Standard pistons were conducted. The main results and conclusions were summarized as follows:

(1) The service life of the mud pump piston with dimpled morphology on the surface improved in comparison with that of the L-Standard piston, and the service life increase percentages were from $4.57 \%$ to $92.06 \%$.

(2) The piston service life would increase with the dimple diameter under the same dimpled arrangement pattern, and the maximum increase in the value of service life was $60.65 \%$.

(3) The service life of the piston with dimples increased by $7.94 \%$ in comparison with that with none.

(4) Under the same dimpled arrangement patterns and area densities, the tighter and closer the dimples were arranged on the piston surface, the longer the service life of piston was, and the maximum increase in the value of service life was $92.06 \%$.
(5) Under the same wear time, the wear of the dimpled piston slightly decreased in comparison with that of the L-Standard piston, and the minimum value of wear mass percentage was $3.83 \%$.

(6) The dimpled shape could not only change the stress state of the piston structure, improve piston wear resistance, and reduce root squeezing, but also increase oil storage space, improve lubricating conditions, and enable the accommodation of some abrasive particles. Furthermore, the dimpled shape was the key factor for the service life improvement of the mud pump piston.

\section{Conflicts of Interest}

The authors declare that there are no conflicts of interest regarding the publication of this paper.

\section{Acknowledgments}

This project was supported by the National Natural Science Foundation of China (Grant no. 51375205).

\section{References}

[1] Z. M. Su, Y. Q. Sun, H. J. Yuan, and J. Y. Guo, "Bayes inference for drilling mud pump piston life," Applied Mechanics and Materials, vol. 295-298, pp. 3142-3147, 2013.

[2] H. M. Yang, M. J. Yang, and B. L. Zhang, "Researches on the mechanism of heel protection of nylon rings for piston of slush pumps," Acta Petrolei Sinica, vol. 4, no. 4, pp. 81-91, 1983.

[3] B. L. Zhang and T. M. Shao, "Investigation of friction and temperature characteristics of mud pump rubber piston," Acta Petrolei Sinica, vol. 9, no. 2, pp. 99-108, 1988.

[4] I. Etsion, "State of the art in laser surface texturing," Journal of Tribology, vol. 127, pp. 248-253, 2005.

[5] I. Etsion, "Improving tribological performance of mechanical components by laser surface texturing," Tribology Letters, vol. 17, no. 4, pp. 733-737, 2004.

[6] I. Etsion, G. Halperin, and E. Becker, "The effect of various surface treatments on piston pin scuffing resistance," Wear, vol. 261, no. 7-8, pp. 785-791, 2006.

[7] L. Q. Ren, "Progress in the bionic study on anti-adhesion and resistance reduction of terrain machines," Science in China Series E: Technological Sciences, vol. 52, no. 2, pp. 273-284, 2009.

[8] L. Q. Ren and Y. H. Liang, "Biological couplings: function, characteristics and implementation mode," Science China Technological Sciences, vol. 53, no. 2, pp. 379-387, 2010.

[9] X. J. Cheng, S. F. Ru, Y. W. Sun, and Q. Cong, "Wear performance of bionic strip-shaped mud pump pistons," Proceedings of the Institution of Mechanical Engineers, Part C: Journal of Mechanical Engineering Science, vol. 231, no. 21, pp. 4076-4084, 2016, in press.

[10] B. Wu, Q. Cong, and P. Xi, "Optimized design of internal engine piston skirt with bionic structure," Transactions of the Chinese Society for Agricultural Machinery, vol. 46, no. 6, pp. 287-293, 2015.

[11] K. Gao, Y. H. Sun, R. F. Gao, L. Xu, C. L. Wang, and Y. M. Li, "Application and prospect of bionic non-smooth theory in 
drilling engineering," Petroleum Exploration and Development, vol. 36, no. 4, pp. 519-522, 2009.

[12] G. Ryk, Y. Kligerman, and I. Etsion, "Experimental investigation of laser surface texturing for reciprocating automotive components," Tribology Transactions, vol. 45, no. 4, pp. 444-449, 2002.

[13] Y. Kligerman, I. Etsion, and A. Shinkarenko, "Improving tribological performance of piston rings by partial surface texturing," Journal of Tribology, vol. 127, no. 3, pp. 632-638, 2005.

[14] A. Ronen, I. Etsion, and Y. Kligerman, "Friction-reducing surface-texturing in reciprocating automotive components," Tribology Transactions, vol. 44, no. 3, pp. 359-366, 2001.

[15] Z. Wu, J. X. Deng, H. Zhang, Y. S. Lian, and J. Zhao, "Tribological behavior of textured cemented carbide filled with solid lubricants in dry sliding with titanium alloys," Wear, vol. 292-293, pp. 135-143, 2012.

[16] Y. Qiu and M. M. Khonsari, "Experimental investigation of tribological performance of laser textured stainless steel rings," Tribology International, vol. 44, no. 5, pp. 635-644, 2011.

[17] V. Brizmer, Y. Kligerman, and I. Etsion, "A laser surface textured parallel thrust bearing," Tribology Transactions, vol. 46, no. 3, pp. 397-403, 2003.

[18] B. Raeymaekers, I. Etsion, and F. E. Talke, "A model for magnetic tape/guide friction reduction by laser surface texturing," Tribology Letters, vol. 28, no. 1, pp. 9-17, 2007.

[19] E. Tomanik, "Modelling the hydrodynamic support of cylinder bore and piston rings with laser textured surfaces," Tribology International, vol. 59, pp. 90-96, 2013.

[20] L. Vandoni, A. G. Demir, B. Previtali, N. Lecis, and D. Ugues, "Wear behavior of fiber laser textured TiN coatings in a heavy loaded sliding regime," Materials, vol. 5, no. 12, pp. $2360-$ 2382, 2012.

[21] A. Ramesh, W. Akram, S. P. Mishra, A. H. Cannon, A. A. Polycarpou, and W. P. King, "Friction characteristics of microtextured surfaces under mixed and hydrodynamic lubrication," Tribology International, vol. 57, pp. 170-176, 2013.

[22] B. C. Chen, L. Q. Ren, X. B. Xu et al., "Initial research on reducing soil adhesion of body surface shapes of the typical soil animals," Transactions of the Chinese Society of Agricultural Engineering, vol. 6, no. 2, pp. 1-6, 1990. 

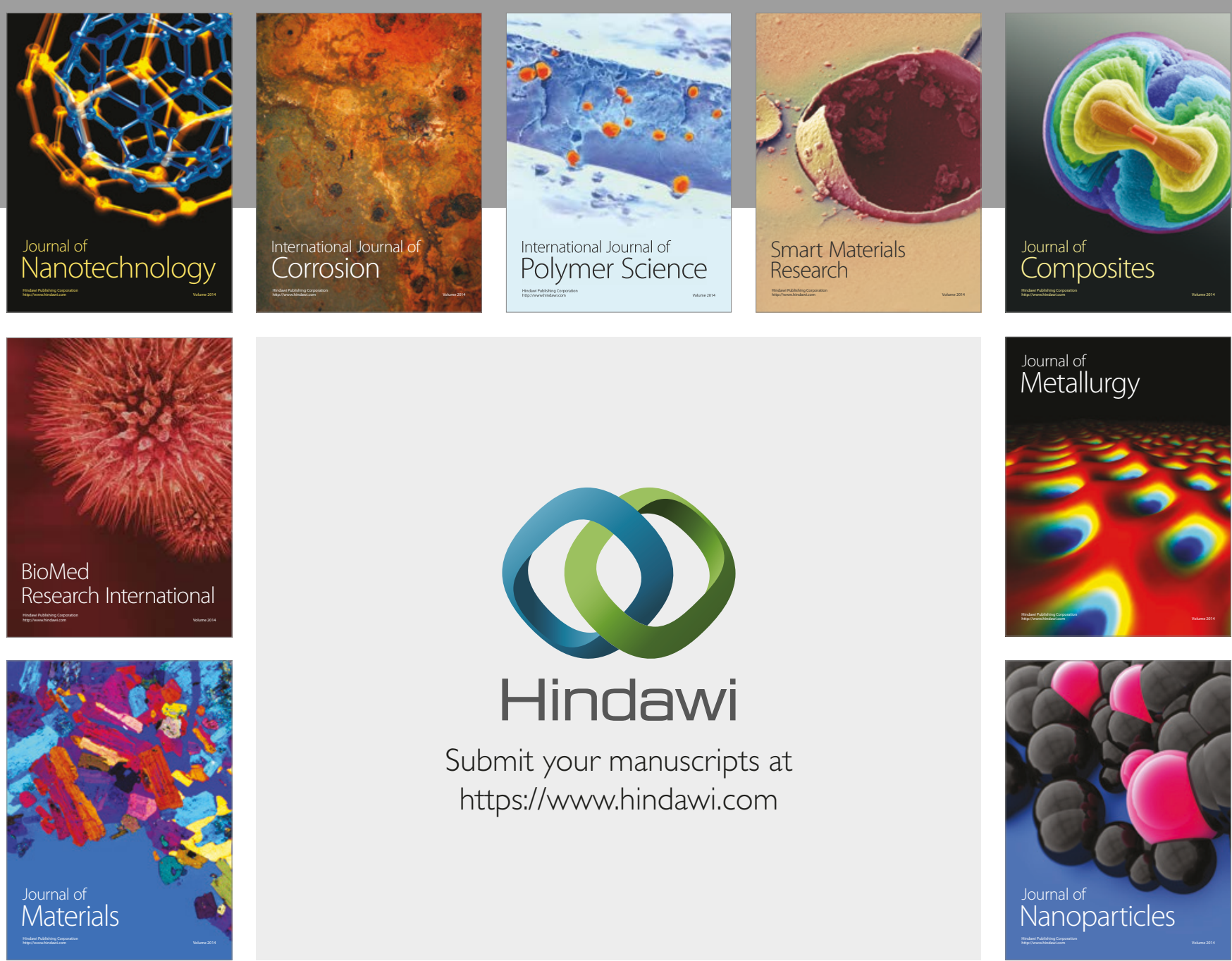

\section{Hindawi}

Submit your manuscripts at

https://www.hindawi.com
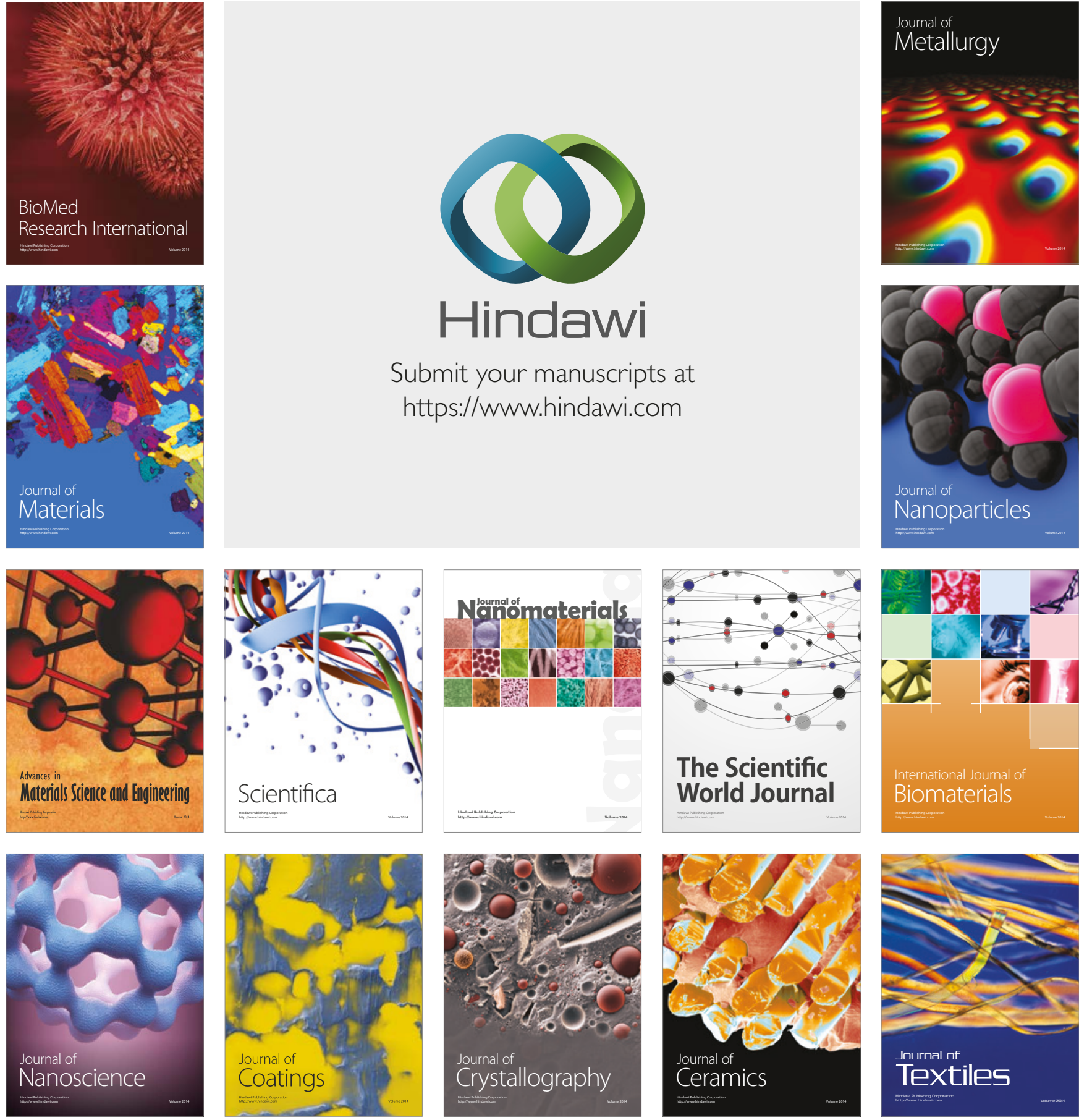

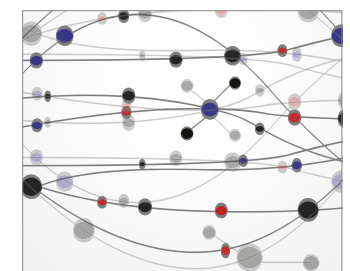

The Scientific World Journal
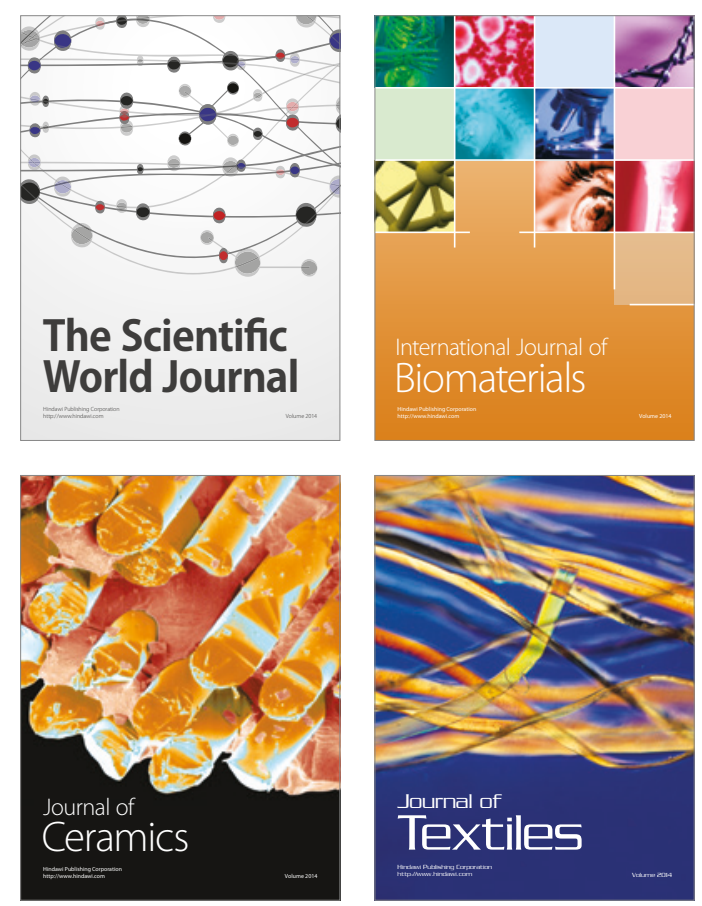